\title{
Recording Radiographic Images on Nitrocellulose Film in Neutron Radiography of Nuclear Reactor Fuel
}

Domanus, J.C.

Publication date:

1987

Document Version

Publisher's PDF, also known as Version of record

Link back to DTU Orbit

Citation (APA):

Domanus, J. C. (1987). Recording Radiographic Images on Nitrocellulose Film in Neutron Radiography of Nuclear Reactor Fuel. Risø National Laboratory. Risø-M No. 2654

\section{General rights}

Copyright and moral rights for the publications made accessible in the public portal are retained by the authors and/or other copyright owners and it is a condition of accessing publications that users recognise and abide by the legal requirements associated with these rights.

- Users may download and print one copy of any publication from the public portal for the purpose of private study or research.

- You may not further distribute the material or use it for any profit-making activity or commercial gain

- You may freely distribute the URL identifying the publication in the public portal

If you believe that this document breaches copyright please contact us providing details, and we will remove access to the work immediately and investigate your claim 


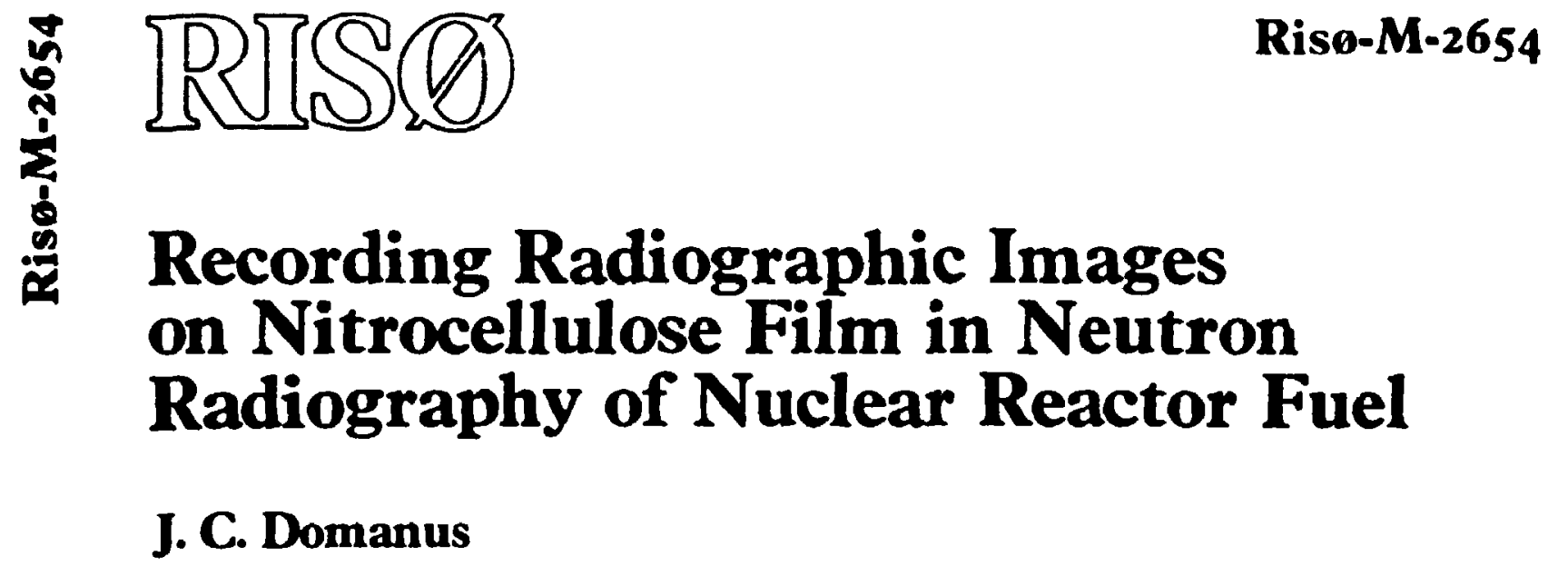

Risø National Laboratory, DK-400o Roskilde, Denmark August 1987 
RECORDING RADIOGRAPHIC IMAGES ON NITROCEIUULOSE FIIM IN MEUTRON RADIOGRAPHY OF NUCLEAR REACTOR FUEL

J.C. Domanus

Mbrtract. Nitrocellulose filn, insensitive to $x$ - and gama-rays (as well as visible light), is especially suitable for neutron radiography of spent nuclear reactor fuel, which iteelf is a source of high-intensity gama-radiation. As nitrocellulose filn is also insensitive to neutrons a converter is necessary to convert neutrons to alpha particles, which in turn are able to produce a radiographic inage on the file. This inage, in the form of minute pits in the film, wust thereafter be made visible by etching the nitrocellulose filn to thereby enlarge the pits so much as to produce a visible inage on the film. After a short description of neutron radiography facilities at various reactor types three mothode of producing neutron radiographs are explained (direct, transfer and track-etch) . Nitrocellulose filn and neutron-to-alpha converters used with it are described. Radiographic image quality of this film is compared with that of silver halide film. A similar comparison is made of the accuracy of dimensional meacuremente from neutron radiographe. 
Accepted for presentation at the Fourth European Conference on Non-Destructive Testing, London, 13-17.09.1987.

ISBA 87-550-1333-3

I884 0418-6435

Graflek service, Rís 1987 
conrentrs

Page

1. INTRODUCTION ............................ 5

2. PRINCIPLES OF nEUTROA RADTOERPAY .............. 6

3. RADIATION sourCes $\ldots \ldots \ldots \ldots \ldots \ldots \ldots \ldots \ldots \ldots \ldots \ldots \ldots \ldots \ldots$ 8.

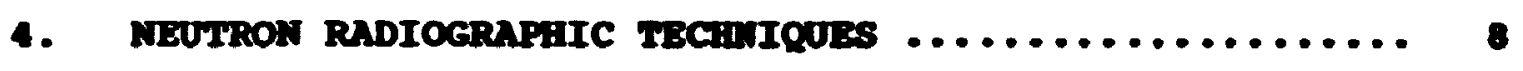

4.1. Direct exposure technique ................... g

4.2. Transfer technique ....................... g

4.3. Track-etch technique ..................... 10

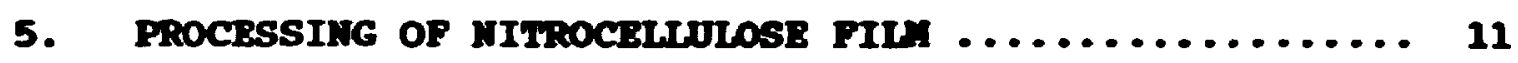

6. VIEWING OF MEUTRON RADIOGRAPAS ............... 12

7. RADIOGRAPHIC IMAgE QUATITY ................. 12

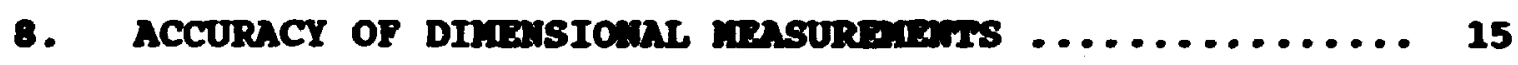

9. Covcusstows $\ldots \ldots \ldots \ldots \ldots \ldots \ldots \ldots \ldots \ldots \ldots \ldots \ldots \ldots \ldots \ldots \ldots \ldots$

9.1. Inage quality $\ldots \ldots \ldots \ldots \ldots \ldots \ldots \ldots \ldots \ldots \ldots \ldots \ldots \ldots . \ldots . \ldots \ldots$

9.2. Dimensional measurcante ............... 17

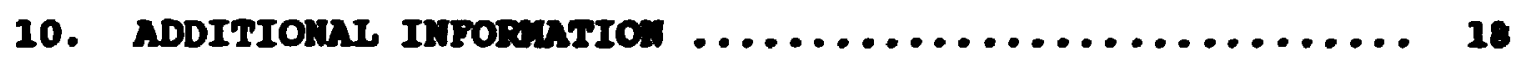

RERRETCES $\ldots \ldots \ldots \ldots \ldots \ldots \ldots \ldots \ldots \ldots \ldots \ldots \ldots \ldots \ldots \ldots \ldots \ldots \ldots \ldots \ldots \ldots \ldots$ 


\section{INTRODUCTION}

There are two main reasons why nitrocellulose film is used in nevtron radiography.

- It can be used as a direct-inaging technique for radioactive objects.

- It produces sharper inages than the eilver halide filn.

Wereas the first advantage of using nitrocellulose fil is self-evident (as the filn is insensitive to the radiation entted by the radioactive object) the second advantage is etill to be proved.

$2 s$ in other fields of industrial radiography inage quality indicators (IQI) are also used in neutron radiography to aceess the guality of the radiographic inage. Up till now such IQIs for neutron radiography were published in one ASTH (1975, 1981, 1986) and one AFroR (1982) standarde. The 1975 and 1981 iseves of the ASTH were designed only for eilver halide filn and the 1986 isoue further restricted the use of the standard to the direct ethod. The Arwor standard (1982) is designed for non radionctive objects.

The ASTH (1986) standard deccribes two types of IQIs: the Bean Purity Indicator (BPI) (which is reetricted to only eingleconted silver halide fil and the direct nethod) and the sensitivity Indicator (8I).

as none of those standarde we intended for use with nuclear reactor fuel the Euratom Heutron Badiography Working Group (Mmin) has designed and produced two epecial indicators for that purpoce: The Bean Purity Indicator-Puel (BPI-F) and the Calibration Fuel Pin (CTP-El). Thowe two indicatore, together with the ASTH Bean Purity Indicator (BPI) and sensitivity Ind1cator (8I) ware tested by all the participants of the Jine under a special test progran. 
One of the ains of this test program is to investigate whether the BPI, BPI-F and SI can be used with nitrocellulose film.

The second ain is to test the accuracy of measuring dimensions from neutron radiographs made on nitrocellulose film.

\section{PRINCIPLES OF NEUTRON RADIOGRAPHY}

Ml radiographic methods, whether they make use of $x$-rays, gama-rays or neutrons, are based on the same general principle: that radiatiaon is attenuated on passing through matter.

Thus, the detection of defects in radiography is based on the obeervation of differences in radiation intensity after passing through the object under examination. This occurs according to the basic law of radiation attenuation:

$$
J=J_{0} e^{-\mu x}
$$

The radiation attenuation coeficient $\mu$ shows a continous curve for $x$-rays (over a wide range of wavelengths). This is not the cace, however, for neutrons and it happens that adjacent atomic number elements such as boron and carbon show for example narked differences in neutron attenuation. Because of this it is possible to detect hydrogen in zirconium. Conversely, dense materials such as lead, tungsten, or uraniun are relatively transparent to neutrons. Another iaportant advantage of neutron radiography is its ability to examine directly radioactive objects such as epent fuel elements. 

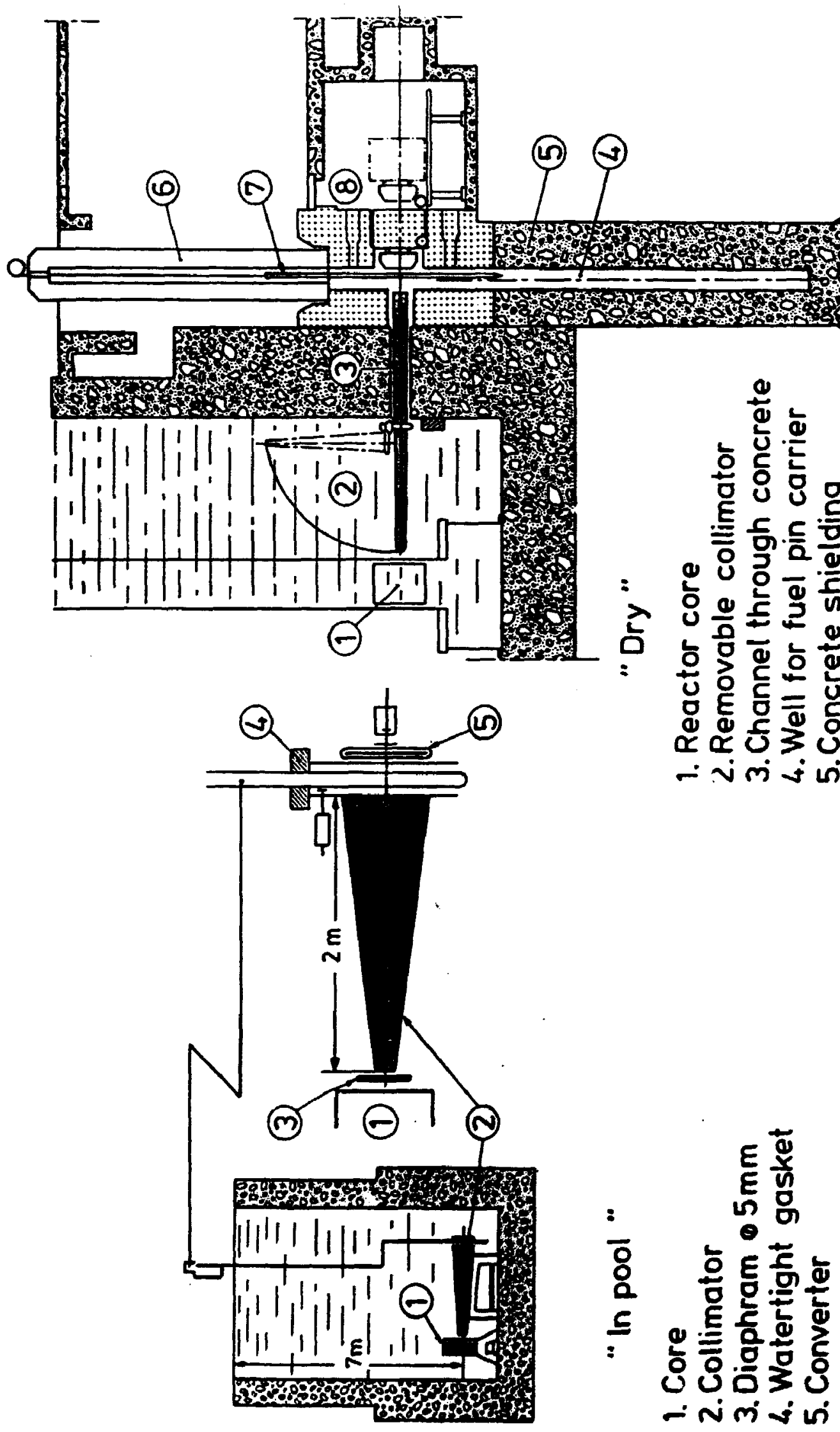


\section{RADIATION SOURCES}

There are three sources of neutrons available for neutron radiography: particle accelerators, radioisotopes and nuclear reactors. Only the latter will be reviewed below. At present nuclear reactors provide the most intense neutron beams and therefore can produce neutron radiographs of the highest quality.

Two types of neutron radiographic facilities are used with nuclear reactors (see fig. 1). In the win poolw facility the whole neutron radiographic installation is imersed in the pool of the reactor. Here, irradiated reactor fuel rods, removed from the reactor core, are transferred to the neutron radiographic facility, where they are examined without removing them from the reactor pool.

In the "drynn type facility, a neutron beam taken out of the core of the reactor is used outside the reactor for neutron radiography.

\section{NEUTRON RADIOGRAPHIC TECHIQUES}

$A$ in $X$ - or gama-radiography, $X$-ray 1 ilm is the nedium for producing neutron radiographs. For radiographing radioactive naterials the nitrocellulose fil is also used.

Unfortunately, neutrons have very little direct effect on photographic film. Thus an intensifying screen of sone kind is needed to increase the speed of the illn. The nitrocellulose I1I muct also be used with a converter screen, as neutrons do not alrectly affect this type of film.

of the many existing methods of recording neutron images, only those wich are widely ueed in practice will be described here 
(see fig. 2). They are the following: the direct and transfer technique using metal converter foils with $x$-ray film and the track-etch technique using nitrocellulose film.

1.1. Direct Exposure Technique. In the direct exposure technique a metal converter foil. is placed in contact with $X$-ray film during the actual exposure (fig. 2). Usually, a single gadoliniu back screen is used. This screen enits gama-radiation on absorbing neutrons. The gamas in the spectrum from gadoliniu are suitable for producing electrons by internal conversion. Those low-energy electrons essentially expose only the amulion facing the gadolinium. Single coated slow $X-r a y$ films are therefore used with the direct technique.

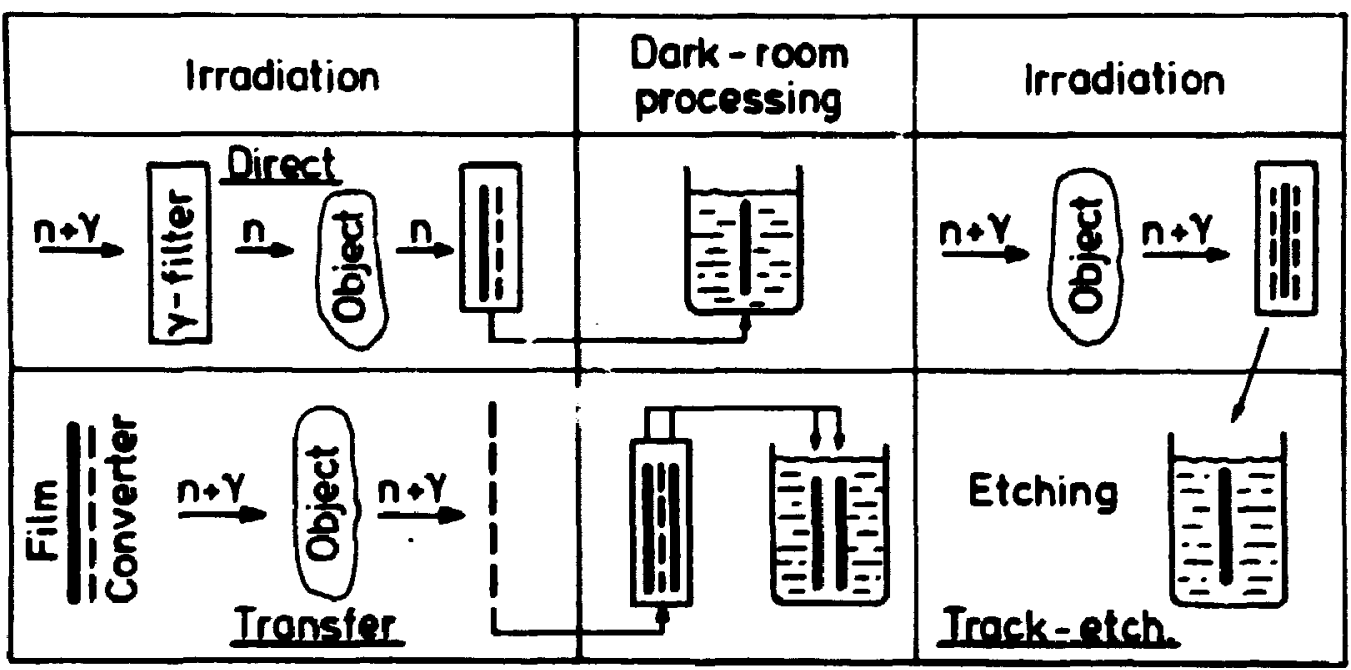

Pir. 2. Neutron radiographic techniques.

4.2. Transen Techntoue. In the transfer technique (fig. 2) only the converter screen is exposed directly to neutrons. The wetal screen placed in the neutron bean becones radioactive in proportion to the intensities in the spatial neutron inage. The ccreen is absequently traneferred from the noutron bean to a darkroon were it is placed in close contact with the $x$-ray 110 using a vacuun cascette. The radioactive anision from the coreen then produces an lage on the $\mathrm{ell}$. 
The transfer method offers the advantage that the film, which is not present in the neutron beam, is neither exposed to gama-radiation from a radioactive object nor from gamma-rays in the neutron beam itself.

The more energetic $\beta$-particles emitted by the transfer screens have sufficient energy to penetrate normal photosensitive film completely. Thus both emulsions of a double coated $x$-ray film will contribute appreciably to the film density and to the unsharpness.

4.3. Track-etch Technigue. For neutron radiography of radioactive objects (such as irradiated nuclear fuel) nitrocellulose film is used as a neutron detector. This is a dielectric material which can detect charged particles by the radiation damage caused in it. Those charged particles are produced by an aenitting converter screen. The radiation damage is made visible by etching in hot sodium hydroxide solution (e.g., in $10 \% \mathrm{NaOH}$ for $45 \mathrm{~min}$ at $\left.50^{\circ} \mathrm{C}\right)$. The nitrocellulose (ilm, sandwiched between two a-emitting converter screens, is placed directly in the neutron beam (fig. 2) as it is insensitive to gama-rays. As the nitrocellulose film is also insensitive to visible light the consecutive etching need not be done in a dark roon.

Hitrocellulose film is available (from Rodak-Pathe, France) for neutron radiography in two $\mathrm{film/converter} \mathrm{varfations.} \mathrm{The} \mathrm{first}$ consists of a $100 \mathrm{~m}$ thick sheet of cellulose nitrate coated on both eldes with lithium borate dispersed in a water-soluble binder, which acts as a converter screen by meane of the $(n, \alpha)$ reaction (CN 85 Type B). After irradiation the lithiu borate coating is rewoved by washing and then the film itself is etched.

The second variation consists of the same ci 85 nitrocellulose 11. (without coating) which is sandwiched between two converter screane (BA 1 ) made erom natural boron, a $(n, a)$ converter. This converter is coated on a 100 m thick, very stable, polyester base and can be reuced indefinitely. The efeiciency of the Bul is higher than that of the CN 85 Type $B$ 
and therefore requires exposure times only slightly longer than those for the transfer technique (with Dy converter and slow $X-$ ray film). To establish perfect contact between the converter and nitrocellulose film the use of a vacuum cassette is essential.

\section{PROCESSING OF NITROCELLULOSE FILY}

Unlike that of the silver halide film the processing of nitrocellulose film can be adapted to the object being radiographed. The processing consists of the etching of the exposed nitrocellulose film in a solution (of various concentrations) of the etching agent at different time/temperature combinations. The most commonly used etching agent is the $108(2.5 \mathrm{~N})$ solution of analytical grade sodium hydroxide in distilled water. As recomended by the film manufacturer the processing conditions may vary from 10 to $30 \mathrm{~min}$ at $60^{\circ} \mathrm{C}$ to 2 to $8 \mathrm{~h}$ at $25^{\circ} \mathrm{C}$ (during the NRWG Test Program the films were etched at $20^{\circ} \mathrm{C}$ for $21 \mathrm{~h}$ and at $50^{\circ} \mathrm{C}$ for $45 \mathrm{~min}$ ). In general when a low-concentration, low-temperature or short etching time is acopted then those parts on the neutron radiographs that have the low attenuation of neutrons will appear. For longer etching times, however, those parts with the higher neutron attenuation will appear nore clearly. This permits the use of the so called gradual processing, where the etching will first be stopped after a shorter time and the radiograph will be viewed to see the parts of lower attenuation, and then the etching will continue until it reaches the time necessary to see the parts that have the highest attenuation of neutrons. 
6. VIEWING OF NEUTRON RADIOGRAPHS

The viewing of neutron radiographs produced by the direct or transfer method on X-ray film creates no special problems.

As the optical density of the etched nitrocellulose film is rather low compared with the film densities of silver halide films used in $x$ - and gama radiography, two additional nethods of viewing neutron radiographs on nitrocellulose filn (besides direct viewing) are used to increase the low contrast of the radiographic image.

The contrast can be significantly improved by printing the nitrocellulose film on high contrast film, using a point source enlarger. However, the nitrocellulose filn can be directly examined by placing it between two polarizing filters (for direat viewing).

7. RADIOGRAPHIC IMAGE QUAIITY

One of the most important factors that is alwaye checked in industrial radiography is the radiographic inage quality. Therefore it will be best to compare the nitrocellulose with the silver halide film by investigating image guality of both. This could be done by the use of inage quality indicators (IQI) - Unfortunately, such IQIs do not exist for noutron radiography performed on nitrocellulose film.

Under the IRWG Test Progran the ASIH ES45 $8 I$ was ueed as an IQI.

The exalinaition of about 150 neutron radiographe of the $8 I$ has show that in more than 96.58 all the $\mathrm{Al}$ shine of the $\mathrm{sI}$ were ceen on all neutron radiographe. Therefore the exarination of the visibility oi $A l$ shime on neutron radiographs is not welective enough to compare the image quality of nitrocellulose and silver halide film. 
The same examination performed about the visibility of holes on the same 150 neutron radiographs of the SI has shown that more holes can almost always be seen on silver halide than on nitrocellulose film. Only on filns exposed on one of the NR facilities could more holes be seen on nitrocellulose filn.

Closing the above remarks about the assessment of the image guality of nitrocellulose $211 \times$ by the use of the ASTI SI one mut stress once more that the ASTM standard was designed only for silver halide film.
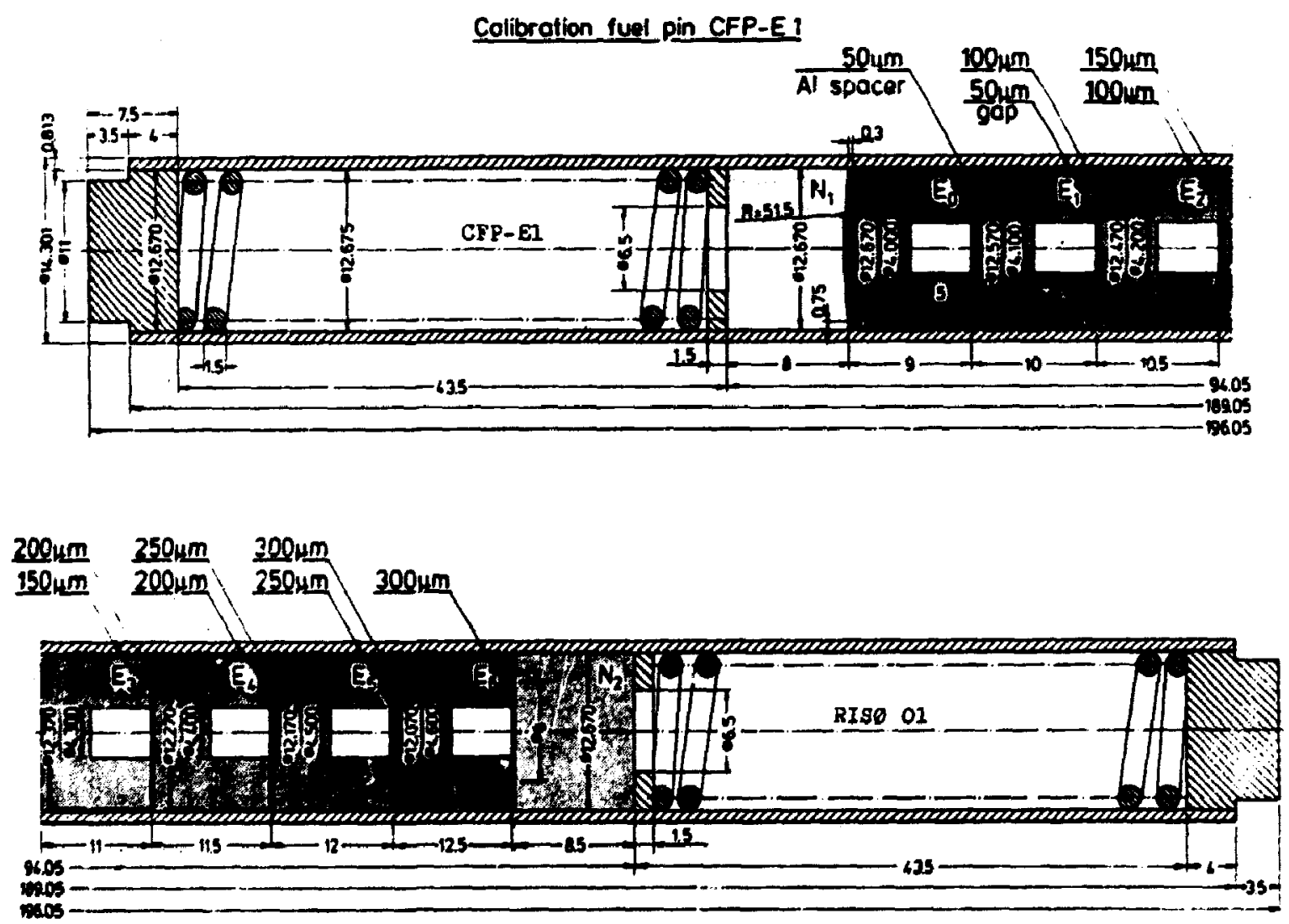

Rife 3. Calibration fuel pin CPP-E1. 
Following the statenent of the ASTH B545 "that the only truly valid sensitivity indicator is a material or component, equivalent to the part being neutron radiographed, with a known standard discontinuity (reference standard comparison part) " a calibration fuel pin (CFP) was designed and produced at Riso (see fig. 3). The first version of this CFP was used as early as in 1976 to check the accuracy of dimensional measurements from neutron radiographs of nuclear fuel pins (Domanus, 1976).

This CFP was thereafter used also for comparing the image quality of nuclear fuel neutron radiographs taken on silver-halide filn and the CA80-15B and CN85B nitrocellulose films (Domanus, 1979).

Finally a sinilar comparison (using the CN85B film) was also reported (Domanus, 1981).

There are several methods to use the CPP for the purpose of ascessing the image quality of neutron radiographs. CFP was especially designed to assess neutron radiographs of nuclear fuel. This is just the field in which nitrocellulose film is nost useful and mostly utilized.

Viewing a neutron radiograph of a CPP one can assess its quality visually. This was previously done and reported using a five grade arbitrary scale of image quality. The highest grade 5 was used, when a neutron radiograph of the CPP was equally sharp as an $X$-ray radiograph of the samea CFP. The poorest neutron radiographs were given the grade of 1 .

The former examinations were 1 imited to only one MR facility (RIs DRI) with a rather low $\mathrm{L} / \mathrm{D}=110$.

Now a larger experimental material is available in the form of about 150 neutron radiographs originating from 11 NR facilities with different $\mathrm{L} / \mathrm{D}$ ratios. The results of this examination were reported by Domanus (1987). 


\section{ACCURACY OF DIHIEASIONAL MASUREMENS}

The second wethod of using the neutron radiographs of the CPPE1 for assessing inage quality consists of naking actual masuranests from neutron radiagraphs of different dimensions of the CPP-BI and comparing then with the true dimensions given in CrP-BI masuring certificate. Fron this comparison conclusions can be drawn about the inage quality of silver halide as well as nitrocellulose filn.

The divensions can be measured using either a projection nicrosoope or a travelling nicrodensitoneter. In the first instance a subjective neasuring wethod is in use whereas in the second objective results are obtained.

During the NRive Test Progran about 25,000 dimensional measurements were made. At eleven neutron radiographic facilities the CrP-BI was neutron radiographed and the radiographe were proceseed and asseseed 402 tines (273 tines with the profile profector and 129 with the travelling wicrodensitometer) using 30 different recording and viewing techniques. The results of those measurenents are now evaluated in three groups by calcrlating standard deviations between the measured and true dinensions:

1) For all the eleven neutron radiography facilities together.

2) For each facility individually.

3) For different groups of dimensions (e.g. pellet diameter, pellet length, pellet-to-pellet and pellet-to-clad gape).

As the results of this evaluation are as yet unavailable, only preliminary conclusions can be dram about the accuracy of dinensional measurements from noutron radiographs. 


\section{9. concuusions}

Whan conparing radiographic inage quality and accuracy of dimansional neasurements of the nitrocellulose filn with those of the silver halide filn one nust renember that the main field of use of the former is neutron radiography of radioactive objects (wuch as irradiated nuclear reactor fuel). Therefore the conparison ought to be done between the track-etch nethod using nitrocelluloce filn, and the transfer nethod using silver halide filn.

2.1. Ince omality. When analyzing the results of the inage quality assessment by the subjective (visual) nethod one can cone to the following conclusions:

- In many instances the quality of the neutron radiographs taken on nitrocel lulose fill was equally good as that on a single-coated silver halide film (exposed by the transfer method using Dy converter), but it was never better;

- In several instances the quality of the neutron radiographs taken on silver halide film by the transfer nethod was better than that of the nitrocellulose film;

- the use of polarizing filters for the visual assessment of inage quality of the nitrocellulose filn did not improve the inage guality; sometimes the guality was equally good as without the polarizing filters, but never better;

- in several instances the quality was better for ch85 type B films (coated with converter on both sides) than for CN85 film sandwiched between two BN1 converters; only in one instance was the reverse true.

- In several instances etching at $20^{\circ} \mathrm{C}$ for $21 \mathrm{~h}$ gave better quality than etching at $50^{\circ} \mathrm{C}$ for $45 \mathrm{~min}$.

As a general conclusion from the visual assessment of radiographic quality one may state that nitrocellullose film is no better than single-coated silver halide film used with the Dy converter and the transfer method. 
2.2. Dinansional masurenents. Fron the partial analysis of rewults obtained from same dimensional measurenents (gaps) of the CrP-El one can cone to the following conclusions:

- almont always the percent deviation between the neasured and true dimensions is much greater for the sall gap (50 m) than for the large one $(300 \mathrm{~m})$,

- for the large gap $(300 \mathrm{~m})$ the largest deviation was $35 \%$ and the anallest 0.38 ,

- wen calculating the above deviations in absolute figure: one will have for the anllest gap the largest deviation $127.5 \mathrm{~m}$ and the sallest deviation of $1 \mathrm{~m}$, whereas for the largest gap the corresponding results will be 105 and $0.9 \mathrm{~m}$,

- most of the measurements have shown larger values than the true dinonsions,

- as could be expected the best results anong the silver halide filme were alnost always obtained with the singlecoated Rodak SR fill.,

- in many instances nitrocellulose films etched at $20^{\circ} \mathrm{C}$ for 21 h gave better results than those etched at $50^{\circ} \mathrm{C}$ for 45 nin; however, this cannot be accepted as a rule and therefore one cannot recomend the use of the one or the other node of etching,

- as for the use of polarizing filters, in many instances the measuring accuracies obtained with them wore better than without them, but the difference was not so convincing as to justify the recomendation of using polarizing filters for dimensional measurements from nitrocellulose filn,

- In general the use of Crss type B filns (coated with converter on both sides) gave better measuring accuracies than those obtained with the crses fill sandwiched between two Bul converters; one must remenber, however, that this latter conbination pernits shorter exposure tines,

- in some instances measuring accuracies obtained with nitrocellulose film were better than those with the best (single coated) silver halide film; the accuracies were not, however, so spectacular as one could expect, 
- on could not find a direct relationship between the accuracy of dimensional mensurementes and the $4 / D$ ratio of different uR facilities.

As a general conclusion from the above neasuring results one can eay that one cannot recomend the use of nitrocellulose fil based only on their ability to give occasionally higher sccuracies in dibensional measurements.

10. NDDITIOUAL Infowarios

Iditional inforation about nitrocellulose filn can be found in a epecial publication dedicated to that subject. It is the 10R report "Heutron Radiography on Nitrocellulose Film", edited by J. Markgraf. It will be published in 1988 as a book by the D. Reidel Publishing $C o$. in their series on neutron radiography.

Inny examples of neutron radiographys of nuclear reactor fuel taten on nitrocellulose filn can be found in another EUR report (published in 1984) by D. Reidel in the series on neutron radiography): "Reference Neutron Radiographs of Nuclear Reactor rue 1", edited by J.C. Domanus.

RETRENCES

Arwor (1982). Norme experimentale N09-220. Neutronographie Industriel1e. Deternination des characteristiques des installations pour controle de pieces non radioactives. Industrial noutron radiography. Determination of the characteristics of tosting facilitios for the control of nonradioactive parts. septeibre 1982 . 
Now 5S45-75. Standard nethod for deternining inage gality in therenl neutron radiographic teoting.

Asil Es45-81. Standard nethod for deternining inge gaality in thernal neutron radiographic teoting.

1514 2545-86. Standard method for deternining inage quality in direct ther al neutron radiographic testing.

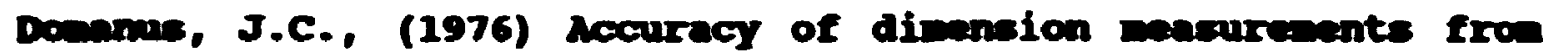
meutron radiographs of nuclear fuel pins. Rise-n-1e60. 23.03.1976 (also as papar 318 presented at the sth World conferance on Nondestructive Testing, Cannes, 6-11.9.1976).

Domanus, J.C., (1979) Comparison of inge guality of nuclear tuel neutron radiographs taken on silver halide and nitrocellu10e film. Risp-H-2170. April 1979 (also as paper 2BDD-1 of the gth World Conference on Non-destructive Testing, Helbourne, 1823.11.1979).

Dosanue, J.C., (1981) How good is nitrocellulose filn for neutron radiography? Reutron Radiography. proce Firft lorld conEerence. San Diego, 7-10.12.1981. D. Reidel Publishing Co., 729-736.

Domanue, J.C., (editor) (1984). Reference nevtron radiodraphs of nuclear reactor fuel. D. Reldel Publibhing Co., Dordrecht/ Doston/Lancaster.

Markgraf, J. (editor) (to be published). Nentron radiography on nitrocellu lore filn. D. Reidel Publishing Co., Dordrecht/Boston/Iondon. 


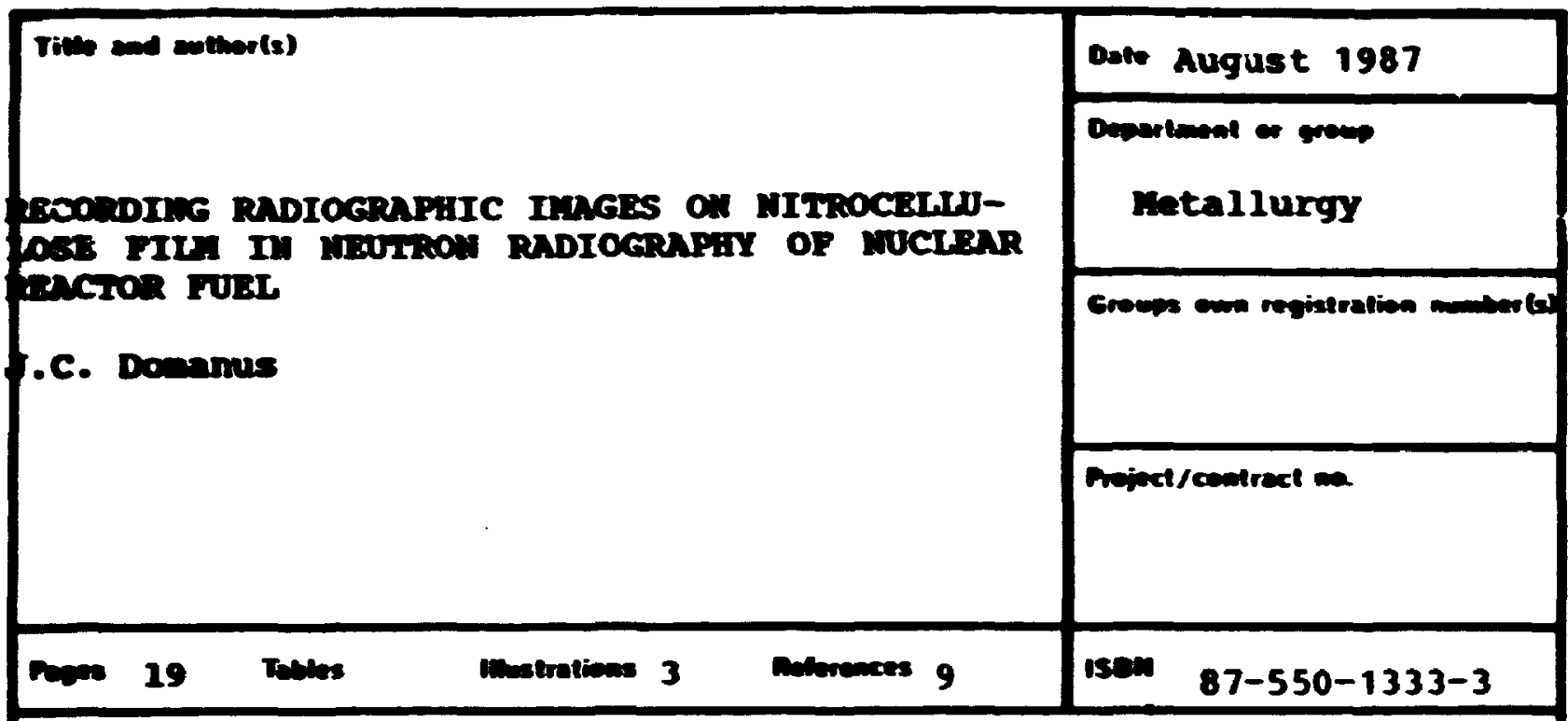

Anponet (man- 2wo chor)

1. tract. Mitrocellulose film, insensitive to $x$ - and gama-rays (as well as visible light), is especially suitable for neutron todiography of spent nuclear reactor fuel, wich itself is a source of high-intensity gam-radiation. As nitrocellulose ill is also insensitive to neutrons a converter is neceseary to cowvert neutrons to alpha particles, which in turn are able to produce a radiographic inage on the filn. This inage, in the for of ninute pits in the filn, wust thereafter be ande viible by etching the nitrocellulose film to thereby enlarge the bite so wuch as to produce a visible inge on the film. After a bort description of neutron radiography facilities at various seactor types three nethods of producing neutron radiographs Ire explained (direct, transfer and track-etch). Nitroceliuloese IIn and neutron-to-alpha converters used with it are decribed. Radiographic inage guality of this filn is compared Ith that of silver halide fill. A sinilar comparison is ade be the accuracy of dimensional measurenents from neutron radiorraphe.

Accepted for presentation at the Fourth European Conference on Non-Destructive Testing, London, 13-17.09.1987.

Deceripters - INIS

ACCURACY; COMPARATIVE EVALUATIONS; ETCHING; IMAGE CONVERTERS; IMAGE PROCESSING; NEUTRON RADIOGRAPHY; NITROCELLULOSE; PHOTOGRAPHIC PILA DETECTORS; SPENT FUEL ELEMENTS 
Avallable on requed from.

Div Lingry,

Riv Nadenal Laboratory, P.O. Bos 41,

DI-4m Reatille, Doments

Prees (C) 871212 ext.2012

ISBN 89-550-1 333-3

ISSN aurectiss 